\title{
ANALYTICS FOR MANAGERS
}

\section{Barnaby Pace and Marianne Cherrington}

\section{INTRODUCTION}

The aim of this paper, Analytics for Managers, is to provide the skills needed to evaluate critically data for decisionmaking within applied management. Learners obtain, relate, analyse and visualise data in managerial decisionmaking contexts, with the help of advanced data analytics techniques. For graduates with a Master of Applied Management, it is particularly important to gain confidence when addressing issues in contemporary business contexts and when justifying analyses in order to provide recommendations for risk management, predicting change, or personalisation. Here, we articulate some of the concepts underpinning analytics by addressing datadriven decision-making opportunities alongside key issues in the transforming world of work. Lessons learned from a post-COVID hybrid delivery of the paper in June and July, 2020, will exemplify some of the larger issues in the work-place such as the role of technology, productivity and up-skilling of the workforce.

\section{RISK VERSUS UNCERTAINTY}

Uncertainty has marked the first half of 2020 and the World Health Organisation (WHO) warns that globally, new COVID-19 cases are accelerating out of control (Tan, 2020). It has been a dirty data deluge, because from an analytics and modelling perspective, the probabilities used in assessing risk are unreliable and normal scientific research regimes have gone 'absent without leave' (Cherrington, Dunn, \& Airehrour, in press).

The world is going through dramatic changes before our eyes and the pace of change is gathering speed. In lockdown, we had a moment to remind ourselves of other socio-economic realities, including the need, or chance, to re-imagine a visionary path for the future of the planet, especially through the choices we make, now. It is more than work-life-balance; we are being forced to reimagine how we work, why we work and our purpose.

For those of us who are grateful to be still employed, we must wonder what will be. For computer science specialists, the future holds endless possibility; artificial intelligence (Al) and machine learning (ML) are actually creating more jobs than they are taking away (a-connect, n.d.). The question is how will we manage that transition? Our workplaces must be creative, agile and visionary; workers must problem solve and navigate issues decisively.

Today's graduates face an open talent economy. The new environment requires flexibility and adaptability (Govindarajan \& Bernstein, 2020). At Otago Polytechnic Auckland International Campus (OPAIC) we use an experiential style in an open plan environment. We are lean and adaptable. We can model this changing world of work, in which problem solving, based on informed realities, leads to better, holistic decisions (Otago Polytechnic, 2020). 


\section{CHANGING THE WAY IN WHICH WE WORK}

If a good model is one that works in practice, traditional models of change are too cumbersome. Two-thirds of change success factors depend on talent (CEB Global, 2016); as the cost of good talent escalates, it makes good sense/cents to focus on people and culture to leverage success in the dynamic world in which we live. Furthermore, three out of four CEOs expect change to be implemented more quickly (CEB Global, 2016). To enable such agility, data-driven decisions are required to understand trends, variation and singularities. The average organisation has undergone five major operational changes in the past three years and three-quarters of firms are expecting more complex change initiatives (see Figure I). Think of the waste: research shows only one third of those initiatives will succeed, and such upheaval takes its toll on organisations (CEB Global, 2016).

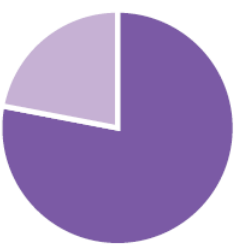

$78 \%$

$$
\begin{aligned}
& \text { Culture } \\
& \text { Change }
\end{aligned}
$$
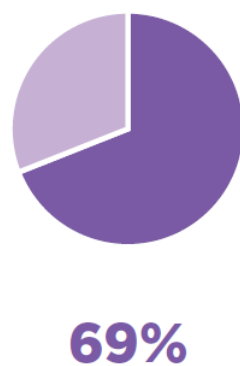

Restructuring
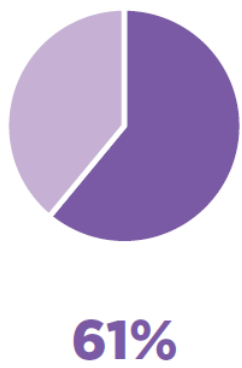

Market Expansion

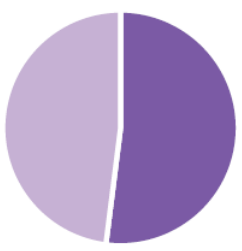

$$
\begin{gathered}
52 \% \\
\text { Leadership } \\
\text { Transition }
\end{gathered}
$$
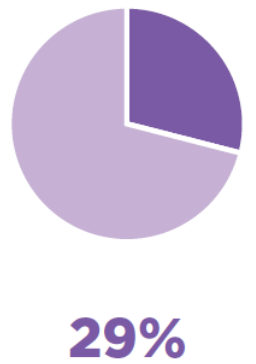

Merger or Acquisition

Figure I. Increasing complexity of organisational change (CEB Global, 2016)

But data can quickly become obsolete. In December 2019, Australia was on fire during their 'Black Summer' and New Zealand was experiencing its 35th straight month of above average temperatures (Morton, 2019). Mother Nature was proving to be a force to be reckoned with; climate change risk and the new Zero Carbon Act were realities that boards of directors were having to contend with (Institute of Directors New Zealand, 2019). Then the new decade arrived: Coronavirus turned the world upside-down. We were fighting for our lives, our jobs and a sense of normalcy.

With Level-four lockdown looming in New Zealand, the shift to online delivery was implemented within days. We survived this crisis well. But do we have employees that are truly capable of rapid change? Are we developing work-ready graduates for these new conditions?

Some of the biggest barriers to change are not skills-based, or even linked with sentiment; empowering perspectives come from an external, future focus (Figure 2). It is also transformational to contemplate that "how people perform correlates to how situations occur to them," so emotion can get us in motion (Zaffron \& Logan, 20II). Good change management is invigorating and good business. Today, data analytics track and motivate empowering sentiment (Papacharissi, 2015). Human computer interaction is part of daily life; learning and capability development intertwine (Otago Polytechnic, n.d.). 


\section{Scott \& Jaffe Change Model}

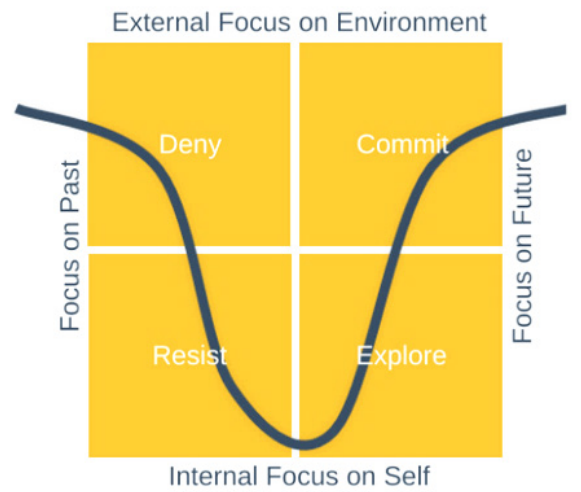

Figure. 2. The Change Focus Continuum (Scott \& Jaffe, 2004)

\section{TECHNOLOGICAL INNOVATION}

We think of innovation as a technology that is software or hardware based. But for most organisations, process improvement is the backbone of all critical developments, where information technology (IT) acts as a driver or tool for business progress. From quality improvement to Total Quality Management and six-sigma, to deep learning, datadriven approaches and methodologies - these have been the back-bone of informed decision-making in leading organisations (Provost \& Fawcett, 20I3). This is how Analytics for Managers differs from analytics papers in an IT qualification. Managers need to speak the language of IT; they must frame problems in analytical contexts to activate data-driven decisions.

Today, the volume, velocity and value of data is almost unimaginable. 'Black box' techniques exist, delivering insights from which decisions with

sweeping consequences are made (Cherrington et al., 2019a, 2019b). We cannot delegate analytics to data scientists, there are not enough even in the pipeline and so too for cybersecurity experts. We deliberate and debate teaching online; however, digital teachers are already taking over (Soul Machines, 2018). Polytechnics are ripe for technological disruption and there is a burning need for learning and teaching to confront the realities of this digital future and the digital world of work already transforming organisations. Digital natives are entering the workforce, so lecturers must creatively navigate complexity to add value (Wang, 2020); qualifications need flexibility, affordability plus creative, technological communications (Govindarajan \& Bernstein, 2020).

\section{LEARNING ANALYTICS}

Analytics turns data into knowledge, resulting from the systematic application of statistics (Figure 3). The study of analytics typically covers computer science data modelling and pre-processing, data driven techniques, and algorithmic techniques. The focus of Analytics for Managers additionally frames problems and uses selected techniques to create data-driven decisions leading to business strategy, with justifications. The basic analytic techniques are not new, but processing power and computational efficiencies as well as analytic platforms allow data to be manipulated in countless ways. Students build their confidence when using business data.
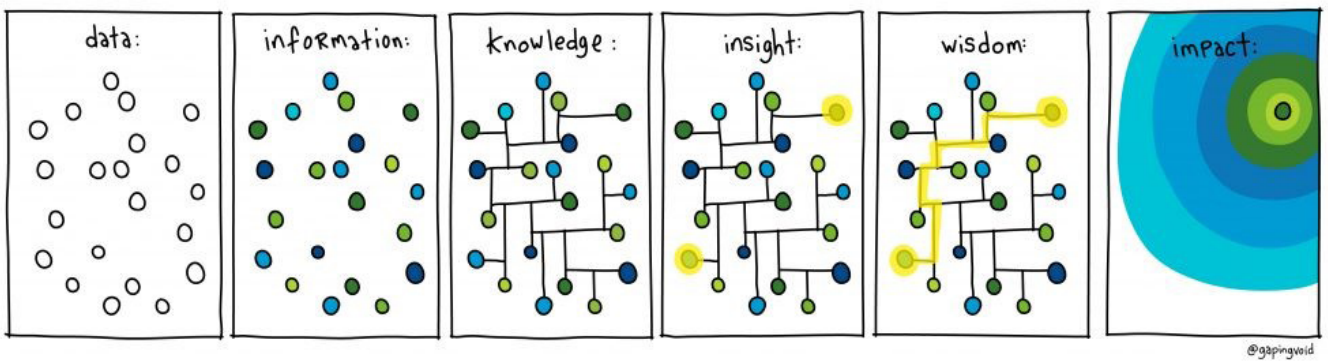

Figure 3. A creative view of 'D-I-K-W' progression, with added insight and impact (gapingvoid.com) 
"Learning is the heart of intelligence" (Cherrington et al., 2019c): machine learning uses advanced analytic techniques like clustering (unsupervised allocation of observations into subsets) and classification (assigning observations into known categories from a training data set) to better identify features of big data (Cherrington et al., 2019c). By understanding differences between these two similar techniques, students can then explore pattern and sequence analysis to better understand 'recommender systems' that personalise offerings when online.

An understanding of these commonplace customer service applications can serve as a basis to appreciate more advanced Al algorithms, robotics, and even digital humans used by industry (Cherrington et al., 2019d, 2019 e). These technologies not only use data to train their algorithms, they gather data with every interaction, as do online and social media sites that firms use in business management. The platforms used in business are realtime processing machines that tech-savvy managers can mine to inform judgements and strategy. First, however, managers need to talk with technology specialists in order to frame problems to attain solutions.

This is the fundamental way in which Analytics for Managers is different from Data Analytics studies in a computer science qualification. For IT students, multifaceted software is used to experiment with various analytic techniques for data reporting, whereas management students need to use simplified techniques that exemplify analysis capabilities. In that way, confidence is developed. The ability to connect issues requiring technological inquiry is fostered by framing organisational issues in the context of data analysis. The uncertainty and necessity of pragmatic decision-making is the ultimate outcome, but nuance is addressed by illuminating how these techniques proliferate in business. The social and cultural issues that envelop data mining are mentioned but are too mammoth to tackle in a two-month paper (Cherrington, 2019).

\section{FRAMING PROBLEMS FOR DECISION-MAKING}

For all the advancement we have made within the sphere of data science and the application of advanced mathematical techniques, Analytics for Managers starts off very simply with how to identify and frame a business/ management problem. This is a basic skill all managers should poses, and yet experience would suggest otherwise. Too often within the business world problems and issues are incorrectly identified, which leads to solutions and decisions which create further problems rather than appropriately addressing the true problem. So the course begins by teaching students how to make data-driven decisions for successfully and productive outcomes.

In total, ten different approaches to how one might frame a problem were delivered to students with examples of how each might present themselves within the management context but not to exclude other areas in which students might find future employment. This set of ten approaches was then distilled down to three methods, moving from a particular approach, dependant on the personal style of the manager, to a series of steps. Anecdotal feedback received from students suggested more comfort with the three methods as concrete steps to follow (not unlike a cookbook), rather than the more subjective natural of ten 'personal managerial style' approaches provided.

What followed on from discussions about the steps required to (I) contextualize the problem, (2) justify the business need, (3) understand the customer or stakeholder, and (4) find the opportunity, was how to effectively and efficiently write problem statements which framed the problem appropriately. Towards the end, students were posed with a series of questions that was to guide them to write concise problem statements (Pace, 20I3, 2015a) which would include all the necessary information for a data-driven solution to be obtained. It was this task beyond any other that was the focus of their first assessment. Weighted at 30 per cent of their final mark, the importance of this skill within Analytics for Managers is evident. 


\section{VISUALISING BIG DATA}

The visualisation of big data, especially with high dimension, is problematic. We can only 'see' in three dimensions; when data is 'collapsed' in two or three dimensions, there can be hidden yet important insights that may be missed or that lead to misinformed conclusions. Yet in many business contexts, these simplified techniques for viewing quantitative and qualitative data are commonplace; results without understanding data are pointless. As with the simple start to Analytics for Managers outlined above, the same approach was taken with data visualisation: get the basics right.

You may well question why a postgraduate course is covering the basics of data visualisation. Surely you are thinking to yourself everyone who completed high school can put a graph together correctly? Sadly, this is not the case. Understanding the basics of graph (or table) construction forms the foundation on which more complexity in data visualisation can be built. Using tutorials to support the lectures, students were guided through correct construction of bar graphs and histograms, pie charts and scatter plots. This included the appropriate use of axis labels, keys, and titles to ensure their presentation in a fully readable format. Predominately Microsoft Excel was used for this visualisation as this is the foremost software used by managers in the workplace. Examples (Pace, 2015b) were also provided using the R statistical programme to offer alternative software packages for those wishing to explore data science further.

With the basics in hand, further lessons expanded the data visualisation toolkit available for students to use and explore. This involved tutorial sessions on the creation of clustering graphs and classification tables through the use of various in-built functions within Microsoft Excel. This not only offered students additional skills to add to their analytics toolkits but further demonstrated some of the computational features in Microsoft Excel that users are unaware of. Basics features such as the 'COUNTIF' and 'VLOOKUP' functions through to installing 'add-ins' such as 'Data Analysis' and 'Solver.' To demonstrate the power of Microsoft Excel to perform data visualisation, 3-D flood and river modelling (Pace \& Whittaker, 2017) was demonstrated to show how such analysis was used in urban and city planning.

\section{ADVANCED ANALYTICS APPLICATIONS}

By the end of the first assessment in Analytics for Managers, students grasped the importance of framing business problems using descriptive statistics analysed with software. At this point, 'lecture' and 'tutorial' delivery roles were swapped in the co-teaching role. From an agile business perspective, this is 'just another day at the office', but a confluence of events created apprehension for students. The lecturer they had known from campus was now changing roles. Also, the Auckland campus was coming 'offline' and back in the classroom; this was not entirely possible for this cohort as several students were unable to procure flights back to New Zealand due to border restrictions. There was also a step change in the level of difficulty in the analysis techniques; basic statistics now took a machine learning twist, as well as a key focus, in the next weighty assessment. Finding data sets appropriate to the task (even when open data websites were provided) seemed to be a reason for the trepidation some students felt. This is a common emotion. Data analysts are trained to communicate difficult quantitative subject matter using language that is relevant to users; this is all part of the learning process that is developed in this paper.

Semantics and personalisation are the way of the future; it is part of the Analytics for Managers discourse and also a balance that must be managed in the context of teaching and learning. To assuage worries felt by some students, it was decided that a hybrid delivery of the paper would continue, with both lecturers available online at the same time. As well, on-campus tutorial sessions were added three times per week. Interestingly, only a few students availed themselves of this opportunity, but the few who did advanced their understanding markedly by sharing their data insights. 


\section{USING ANALYTICS IN A MANAGERIAL CONTEXT}

From regression, cluster and categorisation analyses, students are then shown techniques commonly used by businesses with an online presence. Frequent pattern and sequence analysis by means of market basket examples were used. It is easy to imagine that, for every customer buying groceries, the buying patterns and associations within the big data generated at checkout provide an opportunity for a staggering number of customer insights that would affect the entire operations of the supermarket and its brand. We give that data away freely, especially with every swipe of our loyalty card. This is an everyday example of data analytics.

A simple illustration of a priori probability can be conveyed using Bayes' Rule, as per secondary school statistics class. With a humble $2 \times 2$ table, often used in business, probability analysis can be explored by all students as well as visualised using a tree diagram. Interestingly, tree diagrams lend themselves to problem solving and decisionmaking. For organisations with diverse teams, managers who master these simple yet powerful tools can gain support for data-driven decisions and can convey change as circumstances progress strategically.

Recommender systems are also discussed. When we purchase online, it is now common to have product or service recommendation alerts. It has become an expectation and a mark of excellent customer service, yet it is also a data mining, sales and marketing strategy which affects operational decisions and supply chains. In fact, time is our most precious resource; these recommender systems help us navigate personal decisions daily.

Sentiment analysis has evolved markedly over the last decade. Organisations and the internet are awash with text; emotion can be gleaned from text to ascertain mood, opinion, and trends. This can be analysed to predict and manipulate situations, to pivot them in predetermined ways. Communications can be duly tailored. It should be noted here, that as lecturers, we do discuss privacy and ethical issues, yet the need for social science specialists has never been more imperative. This should be considered as part of diversity planning within firms.

\section{VISIONARY STRATEGIC LEADERSHIP}

New Zealand has long been under-performing in productivity metrics (Earle, 20l0). This should not be the case. New Zealanders are known for their 'can-do' spirit, and the means to exploit a new digital future already exists. The COVID-19 lockdown was a "crisis-driven opportunity to reset people's minds about what technology really does enable" (Parker, 2020). This should not be taken lightly; it is a pathway for growth using a bigger platform. The 'tyranny of distance' is an opportunity to work as the world sleeps to improve productivity and to create highwage employment. This is the real aim behind studying Analytics for Managers; focussed, tech-savvy firms with a digitised value chain will not only survive but thrive in a post-Covid era, even while we await a vaccine.

The best students will not only solve business issues with data analytics, they will use their insights to make an impact. The recommendations that students create will have analytic engineering perspective with managerial power. This will be delivered as a 'digital customer strategy' for a data analytic focus in tandem with a business strategy that works alongside organisational processes. It will be a process or flowchart visualisation that will integrate the recommendations students make for the industry or organisational issues they have sought to resolve. It will be a learning and development exercise for some, and an insightful amalgamation of knowledge that students bring with them through their studies and experiences. This is difficult to bring to life online and using chatrooms, but for those students who did use 'study buddies' or share in lively on campus discussions, the sharing of knowledge enriched their analyses and elevated the tone of their reports. Maybe that is why firms exist - "they can develop intellectual resources ... from company-specific knowledge to specialised skills that cannot be developed by individuals acting on their own or working through the market" (The Economist, 2013). 


\section{CONCLUSIONS}

Analytics for Managers is not an IT paper; it is a management paper that helps graduates better understand data-driven problem solving that leads to more specific and personalised, data-driven decisions. It is a step into the future, where agile firms value talent and diversity for the insight and impact graduates can deliver from a humble D-I-K-W paradigm (Figure 3). Managers manage people, a firm's most valuable and malleable asset. This requires an understanding of change management and for more visionary leadership within organisations. Soon we will be mining text data within firms for semantic analysis; "leaders listen for the future of their organisation" (Zaffron \& Logan, 20II) and the brightest future materialises when semantics connects with commitment (Figure 3). Data-driven decisions are more than statistics and pie charts: when managers empower synergies within firms in visionary ways, we will be pulled into a better way to work. After all, creative destruction is accelerating and learning and teaching must be part of that new vision.

Barnaby Pace is a Senior Lecturer at Otago Polytechnic AIC. He is a seasoned academic with extensive experience in teaching and learning practices in the delivery of postgraduate courses in applied management and information technology. He is an active researcher in the field of cybersecurity and in the application of theoretical models to solve 'real world' problems with the aim of moving theory to practice.

(D) https://orcid.org/0000-0002-76/1-646X

Marianne Cherrington is a Senior Lecturer at Otago Polytechnic AIC, studying Computer Science and Analytics. A lecturer in disruptive innovation, her research into machine learning feature selection algorithms applies in many fields, and produces interesting collaborations with international partners in many disciplines and sectors.

(D) https://orcid.org/0000-0002-1240-2010

\section{REFERENCES}

a-connect. (n.d.) Everything you need to know about the changing world of work and how to keep abreast with changes as they happen, according to the Economist. Retrieved from https://www.a-connect.com/knowledge/everything-you-need-to-know-aboutthe-changing-world-of-work-according-to-the-economist/

CEB Global (2016). Making Change Management Work (white paper). Retrieved from https://www.cebglobal.com/content/ dam/cebglobal/us/EN/best-practices-decision-support/human-resources/pdfs/making-change-management-workwhitepaperl.pdf

Cherrington, M. (2019). Environmental Social and Governance Sustainability - Ka Mua, Ka Muri. Scope: Contemporary Research Topics (Learning \& Teaching), (8)

Cherrington, M., Lu, J., Airehrour, D., Thabtah, F., Xu, Q., and Madanian, S. (2019a) Feature Selection: Multi-source and Multi-view Data Limitations, Capabilities and Potentials. Proceedings of 29th International Telecommunication Networks and Applications Conference. https://doi.org/I0.1109/ITNAC46935.2019.9077992

Cherrington, M., Airehrour, D., Lu, J., Xu, Q., Wade, S. and Madanian, S. (2019b). Feature Selection Methods for Linked Data: Limitations, Capabilities and Potentials. Proceedings of 6th IEEE/ACM International Conference on Big Data Computing Applications and Technologies (BDCAT) IEEE. https://doi.org/I0.1/45/3365109.3368792

Cherrington, M., Thabtah, F., Lu, J., \& Xu, Q. (2019c, April). Feature Selection: Filter Methods Performance Challenges. International Conference on Computer and Information Sciences, ICCIS 2019 (pp. I-4). IEEE. https://doi.org/I0.1I09/ICCISci.2019.87/6478

Cherrington, M., Lu, Z., Xu, Q., Thabtah, F., Airehrour, D., \& Madanian, S. (2019d). Digital asset management: new opportunities from high dimensional data-a New Zealand perspective. 32nd International Conference on Condition Monitoring and Diagnostic Engineering Management (COMADEM). https://doi.org/I0.1007/978-3-030-57745-2_16

Cherrington, M., Lu, Z., Xu, Q., Airehrour, D., Madanian, S., Dyrkacz, A., Deep Learning Decision Support for Sustainable Asset Management. 32nd International Conference on Condition Monitoring and Diagnostic Engineering Management (2019e). http:// doi.org//0.1007/978-3-030-57745-2_45 
Cherrington, M., Dunn, I., \& Airehrour, A., (in press). Cracking the Covid-19 Code: Cutting-edge Collaboration. Scope: Contemporary Research Topics (Learning \& Teaching), (9). 2020. Dunedin, New Zealand: Otago Polytechnic.

Earle, D. (20I0). How can tertiary education deliver better value to the economy? (Tertiary education occasional paper 2010/08). Ministry of Education. Retrieved from https://www.educationcounts.govt.nz/__data/assets/pdf_file/0004/86980/value-oftertiary-education.pdf

Govindarajan, V., \& Bernstein, A. (2020, May 21). COVID-19's Impact on the Future of Higher Education: What University Leaders Should Be Thinking About Now [Video file]. Harvard Business Review. Retrieved from http://academic.hbsp. harvard.edu/webinar_COVID-19_impact_on_the_future_of_higher_education

Otago Polytechnic. (n.d.). I am capable. Retrieved from https://www.op.ac.nz/students/i-am-capable/

Institute of Directors New Zealand. (2019, October 31). Boards should be aware of, and mitigate for, impacts of climate change risks [Press release]. Retrieved from www.iod.org.nz/resources-and-insights/news-and-articles/iod-boards-should-be-awareof-and-mitigate-for-impacts-of-climate-change-risks/\#

Morton, J. (2019, December 29). Climate changed: December our 35th straight month of higher temps. The New Zealand Herald, p. A5.

Pace, B. (2013). The logical construction of a robust risk statement. Risk Post - The Journal for the Society of Risk Management, 13(4), 8-9.

Pace, B. (20I5a). Revisiting the use of predicate logic in the construction of risk statements, Risk Post - Journal of Risk New Zealand, 14(2), $15-18$.

Pace, B. (20I5b). 'R' is for risk management. Risk Post - Journal of Risk New Zealand, 15(I), 9-II.

Pace, B., \& Whittaker, N. (2017). Increasing Community Resilience through the Inclusion of Climate Change Modelling within Regional Hazard Mapping. Practical Insights, 7, 14-15.

Papacharissi, Z. (20I5). Affective publics: Sentiment, technology, and politics. London: Oxford University Press.

Parker, T. (2020, June 27). Embracing the mobile mentality. The New Zealand Herald, p. C5.

Soul Machines. (2018, September 18). Press: World's first digital teacher starts work teaching kids about energy. Retrieved from www.soulmachines.com/news/2018/09//8/press-worlds-first-digital-teacher-starts-work-teaching-kids-about-energy/

Provost, F., \& Fawcett, T. (20I3). Data science and its relationship to big data and data-driven decision making. Big data, I(I), 5 I-59.

Scott, C. D., \& Jaffe, D. T. (2004). Managing personal change: Moving through personal transition. Singapore: Thomson Crisp Lng.

Tan, L. (2020, July II). Covid 19 coronavirus: WHO warns virus 'accelerating' out of control as global cases reach 1 I.8 million. The New Zealand Herald, p. C5.

The Economist. (2013, September 7). The man who showed why firms exist. Retrieved from www.economist.com/ leaders/2013/09/07/the-man-who-showed-why-firms-exist

Wang, R. (2020, June). How to lead a data-driven digital transformation [Webinar]. Alterix. https://hbr.org/webinar/2020/05/ how-to-lead-a-data-driven-digital-transformation

Zaffron, S., \& Logan, D. (201I). The three laws of performance: Rewriting the future of your organization and your life. John Wiley \& Sons. 